\title{
An Extension-Distraction Injury of the Thoracic Spine with Traumatic Partial Correction of Thoracic Kyphosis
}

\author{
Brad A. Culotta ${ }^{1}$ Donald A. Deinlein ${ }^{1}$ Steven M. Theiss ${ }^{1} \quad$ Jack E. Lemons ${ }^{2}$ \\ ${ }^{1}$ Division of Orthopedics, University of Alabama at Birmingham, \\ Birmingham, Alabama, United States \\ 2 Division of Dentistry, University of Alabama at Birmingham, \\ Birmingham, Alabama, United States \\ Address for correspondence Donald A. Deinlein, MD, Division of \\ Orthopedics, University of Alabama at Birmingham, FOT 960, 510 20th \\ Street South, Birmingham, AL 35294, United States \\ (e-mail: ddeinlein@uabmc.edu).
}

Evid Based Spine Care J 2013;4:126-131.

\begin{abstract}
\section{Keywords}

- osseointegration

- bone-screw interface

- superelasticity

- pseudoplasticity

Study Design The study is a case report.

Objective The authors aim to report an unusual injury pattern in a patient previously treated for thoracic kyphoscoliosis.

Methods A postoperative (computed tomography) CT of a healthy 24-year-old man who underwent posterior instrumentation and fusion for a kyphoscoliosis deformity was compared with a CT performed after a motor vehicle accident (MVA) 1 year later, which resulted in an extension-distraction injury of T8 with no neurologic deficit. Cobb angles of the thoracic sagittal images of both CTs were measured using a digital measuring device and the values were recorded.

Results Initial postoperative sagittal CT images demonstrate a 67-degree residual thoracic kyphosis compared with the post-MVA sagittal CT images, which reveal a 54degree thoracic kyphosis, a 13-degree improvement in sagittal alignment.

Conclusion It is unusual for a patient with long posterior instrumentation of the spine to sustain a spinal fracture without breakage of the rods, which were 6-mm nickeltitanium alloy with two crosslinks. Although sustaining plastic deformation, the rods maintained their integrity to the degree that the patient required no subsequent treatment to his spine at 12 months follow-up. It is rare to sustain a vertebral fracture without implant failure, which occurred in this case.
\end{abstract}

\section{Introduction}

Surgical management of adult patients with spinal deformity often involves posterior instrumentation such as rod-screw constructs. Behavior of this instrumentation when patients sustain traumatic spinal injury often involves implant failure. This is the result of the biomechanical properties of the spine and spinal instrumentation as well as the mechanical load sustained at the time of injury.

received

December 20, 2012

accepted

April 10, 2013

\section{Report of Case}

An otherwise healthy 24-year-old man underwent posterior spinal surgery for adult acquired kyphoscoliosis. Surgical reconstruction included instrumentation and fusion with nickel-titanium pedicle screw-rod construct from T2 to L2 with Smith-Petersen osteotomies at T7-T8, T8-T9, T9-T10, $\mathrm{T} 10-\mathrm{T} 11, \mathrm{~T} 11-\mathrm{T} 12$, and T12-L1. His postoperative course was uneventful and postoperative CT imaging demonstrated

(c) 2013 Georg Thieme Verlag KG Stuttgart · New York
DOI http://dx.doi.org/ 10.1055/s-0033-1347132. ISSN 1663-7976. 


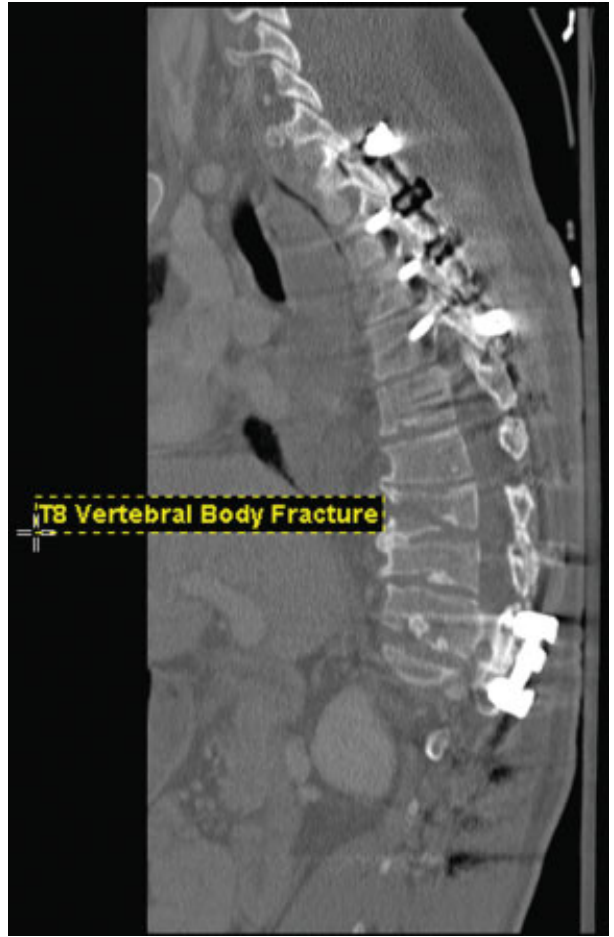

Fig. 1 Sagittal spine computed tomographic image obtained immediately after the MVA demonstrates T8 vertebral body fracture involving the superior and inferior endplate.

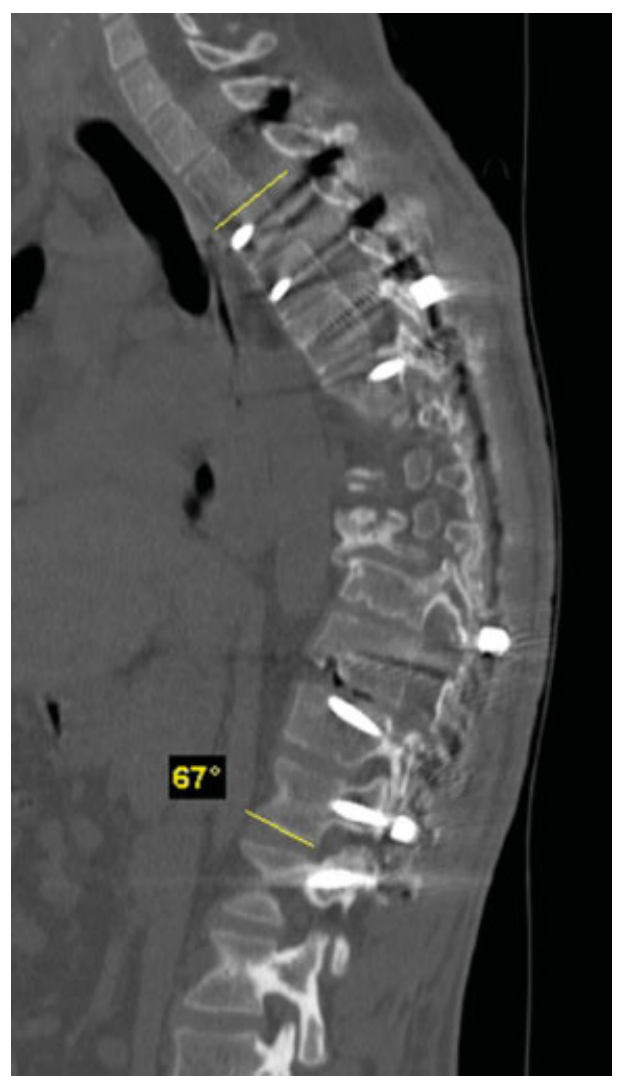

Fig. 2 Cobb angle measurement (superior endplate T3 to inferior endplate T12) on sagittal spine computed tomographic image obtained 3 months postsurgery but prior to MVA demonstrates a residual thoracic kyphosis of 67 degrees.

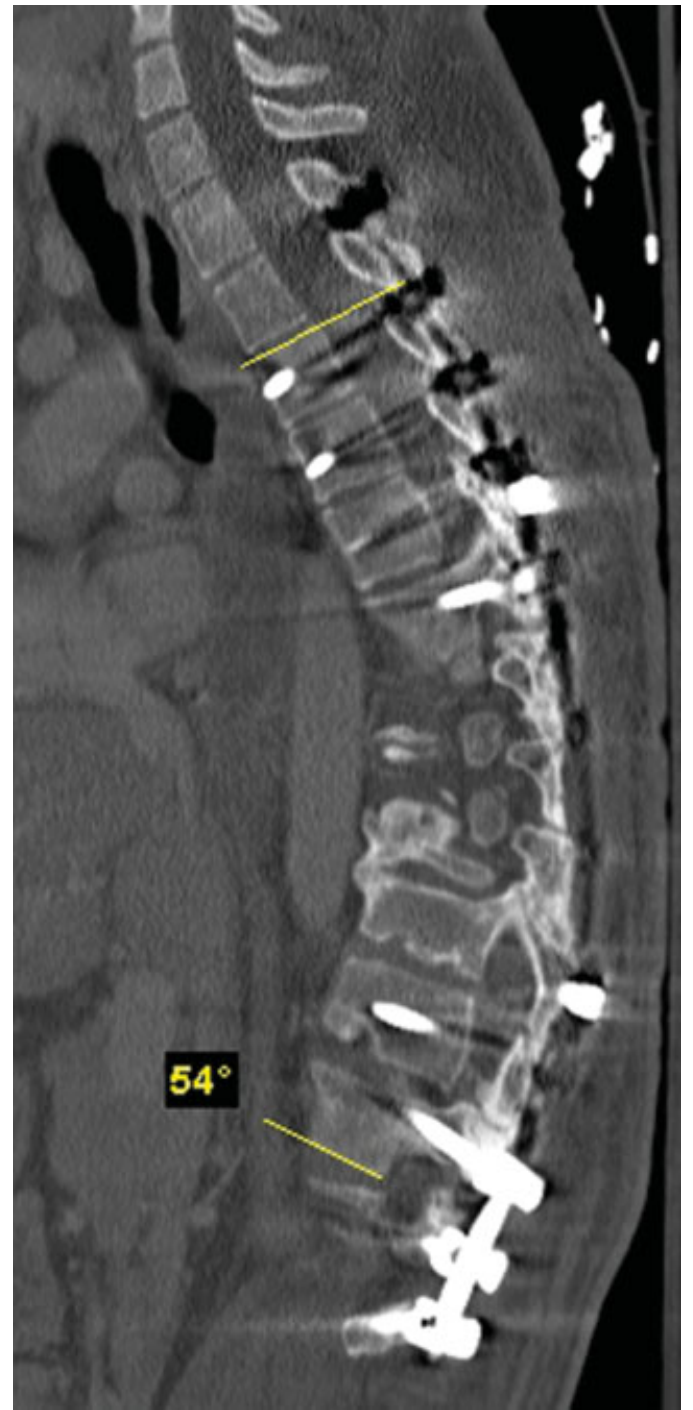

Fig. 3 Cobb angle measurement (superior endplate T3 to inferior endplate T12) on sagittal spine computed tomographic image obtained immediately after the MVA demonstrates a partial correction of thoracic kyphosis to 54 degrees (previously 67 degrees).

correction of scoliosis from 65 degrees to 20 degrees, with a persistent thoracic kyphosis of 67 degrees.

One year later the patient, an unrestrained driver who was ejected from the vehicle, sustained an extension-distraction injury with T8 vertebral body fracture seen on CT imaging (-Fig. 1). He also sustained a right subtrochanteric femur fracture, left clavicle fracture, and left fibular fracture. There was no neurologic deficit postinjury.

Postoperative computed tomographic (CT) images with 2$\mathrm{mm}$ cuts to verify screw placement were compared with $\mathrm{CT}$ images with 2-mm cuts obtained after the motor vehicle collision to evaluate injury to the spinal column. Cobb angles of the thoracic sagittal images were measured using a digital measuring device and the values were recorded.

Initial postoperative sagittal CT images demonstrate a 67degree residual thoracic kyphosis (-Fig. 2) compared with the post-motor vehicle accident (MVA) sagittal CT images, which reveal a 54-degree thoracic kyphosis ( - Fig. 3) and a 13-degree improvement in sagittal alignment. The measurement of the 


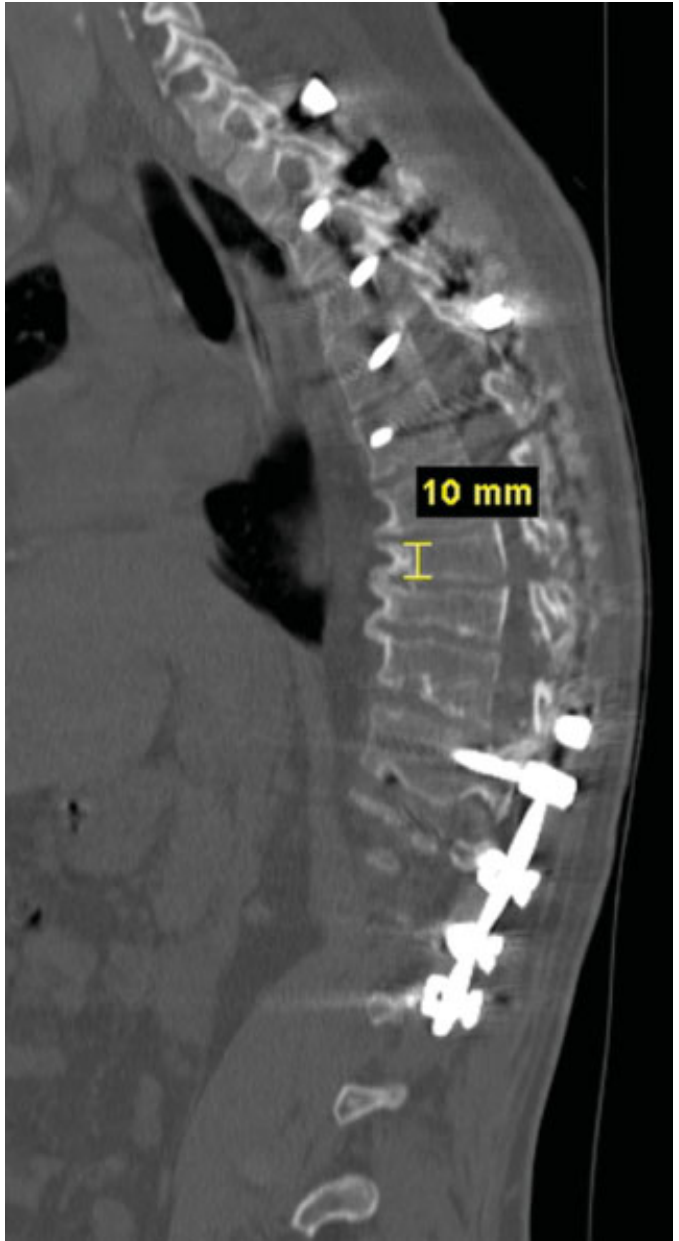

Fig. 4 Measurement of the anterior T8 vertebral body pre-MVA.

anterior height of T8 vertebral body reveals an increase in height from 10 to $18 \mathrm{~mm}$, an increase of $80 \%$ (-Figs. 4 and $\mathbf{5}$ ).

\section{Discussion}

It is unusual for a patient with long posterior instrumentation of the spine to sustain a spinal fracture without breakage of the rods. ${ }^{1-4}$ In this particular case, the rods were $6-\mathrm{mm}$ nickel-titanium (Ni-Ti) alloy with two crosslinks. Although sustaining plastic deformation, the rods maintained their integrity to the degree that the patient required no subsequent treatment to his spine at 12 months follow-up and has remained neurologically intact.

The biomechanical events of this case can be correlated to the biomechanical properties of $\mathrm{Ni}-\mathrm{Ti}$ alloy. There are two characteristics of this alloy that contributed to the observed clinical event, namely, the mechanical properties of the material as well as the likelihood of osseointegration of the pedicle screws. ${ }^{5,6}$ Stress versus strain relationships are shown schematically for implant grade cobalt and stainless steel (Co and $\mathrm{Fe}$ ), titanium (Ti-Al-V), and $\mathrm{Ni}-\mathrm{Ti}$ alloys $^{7}$ (-Figs. 6 and 7). ${ }^{8-11}$ Under the conditions of same size, shape, and crosslinks with similar fixation, stress versus strain relationships are proportional to load versus deformation. ${ }^{6,12}$

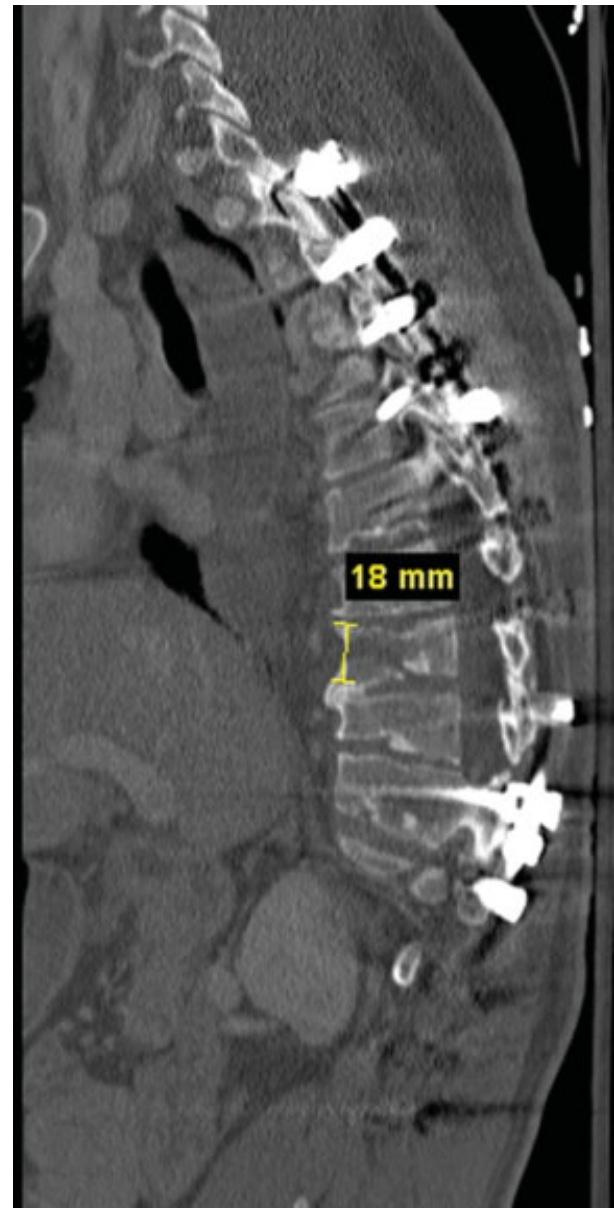

Fig. 5 Measurement of the anterior T8 vertebral body post-MVA.

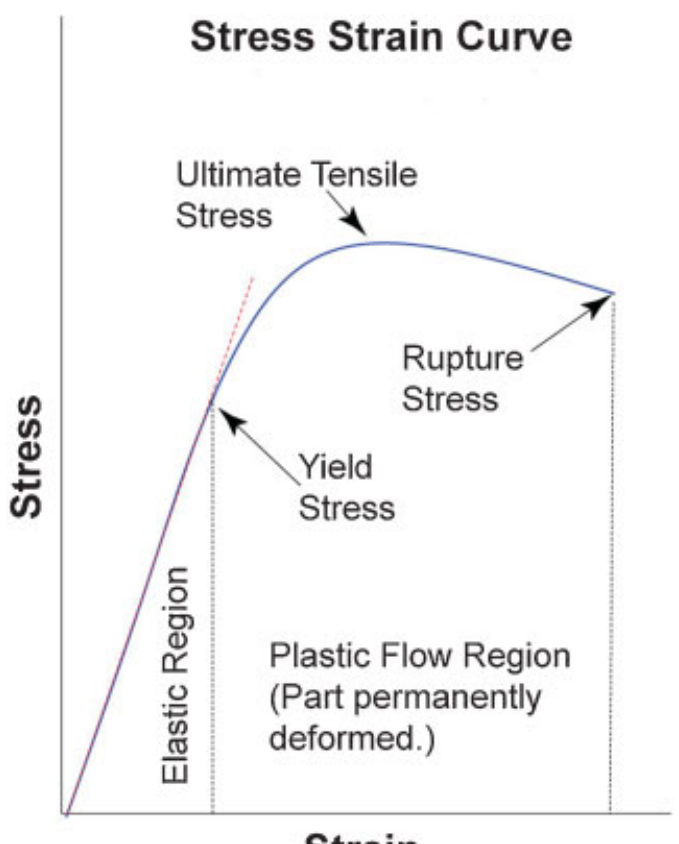

\section{Strain}

Fig. 6 Stress versus strain curve. Titanium alloy, which is capable of bone-screw integration, can provide greater deformation at the same in vivo load without system (construct) breakdown. 


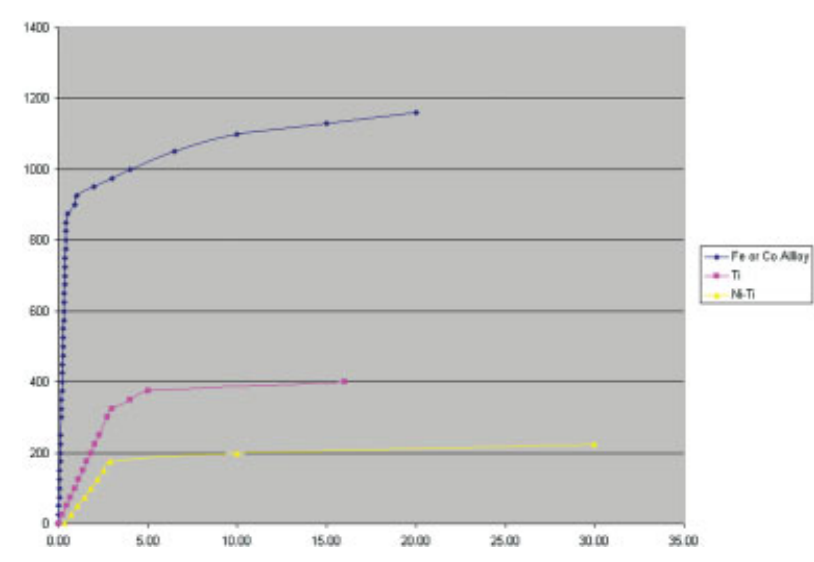

Fig. 7 Schematics of stress versus strain of metallic implants (EL, elastic limit). The initial segments of the curves up to the EL show the elastic modulus (linear portion) is lowest for $\mathrm{Ni}-\mathrm{Ti}$ and highest for cobalt and stainless steel alloys. Thus, for any applied elastic stress (load), the strain (deformation) is highest for $\mathrm{Ni}-\mathrm{Ti}$. Also, $\mathrm{Ni}-\mathrm{Ti}$, in addition to being superelastic, also exhibits pseudoplasticity, which is reflected as increased strain (deformation) without significant increase in stress (load) as represented by the horizontal portion of the curve for $\mathrm{Ni}-\mathrm{Ti}$. Co, Fe, and Ti-Al-V alloys exhibit neither superelasticity nor pseudoplasticity.

Under the conditions where the bone-screw interface is osseous, integrated with mature bone as with $\mathrm{Ni}-\mathrm{Ti}$, and remains integrated during loading, the highest capacity for strain (deformation) without mechanical failure resides with $\mathrm{Ni}$-Ti. The induced deformation beyond the elastic limit for $\mathrm{Ni}-\mathrm{Ti}$ is permanent, and in this case, the rod assumed a new and permanent contour, maintaining the spine in a corrected position.

When bone-screw integration is combined with the plastic attributes of $\mathrm{Ni}-\mathrm{Ti}$, greater deformation at the same in vivo load without construct breakdown can be predicted. ${ }^{6} \mathrm{Ni}-\mathrm{Ti}$ alloy would appear to demonstrate biomechanical advantages of plastic deformation and bone integration that rivals stiffer alloys, such as cobalt and stainless steel, as demonstrated in this case. ${ }^{13,14}$

Thus, an unusual extension-distraction injury of the spine is presented, which in this case, demonstrated improved sagittal alignment after trauma. To our knowledge, there are no reports of this observed phenomenon in the spine literature.

\section{Funding}

No funding was received for this study.

\section{Note}

Approval from Institutional Review Board and informed consent of the patient participating in this study were obtained. The device discussed in this study is approved by Food and Drug Administration for such indication.

\section{References}

1 Frei H, Oxland TR, Nolte LP. Thoracolumbar spine mechanics contrasted under compression and shear loading. J Orthop Res 2002;20(6):1333-1338

2 McAfee PC, Weiland DJ, Carlow JJ. Survivorship analysis of pedicle spinal instrumentation. Spine (Phila Pa 1976) 1991;16(8(Suppl): S422-S427

3 Deen HG, Nottmeier EW, Reimer R. Early complications of posterior rod-screw fixation of the cervical and upper thoracic spine. Neurosurgery 2006;59(5):1062-1067, discussion 1067-1068

4 Elgafy H, Bellabarba C. Three-column ligamentous extension injury of the thoracic spine: a case report and review of the literature. Spine (Phila Pa 1976) 2007;32(25):E785-E788

5 Jiang XH, Zhang Y, Han X, Liu JH, Ma TC. [Histological observation of microscrews anchorage implant-bone interface loaded with different orthodontic condition]. Shanghai Kou Qiang Yi Xue 2008;17(6):621-624

6 Hernández R, Polizu S, Turenne S, Yahia L. Characteristics of porous nickel-titanium alloys for medical applications. Biomed Mater Eng 2002;12(1):37-45

7 Einhorn TA, O’Keefe RJ, Buckwalter JA, eds. Orthopaedic Basic Science Foundations of Clinical Practice. 3rd ed. Rosemont, IL: American Academy of Orthopedic Surgeons; 2007

8 Mow V, Flatow E, Foster R. Biomechanics. In: Simon S, ed. Orthopaedic Basic Science. Chicago, IL: ASOS Pub; 1996:406408, 413-422

9 Litsky A, Spector M. Biomaterials. In: Simon S ed. Orthopaedic Basic Science. Chicago, IL: ASOS Pub; 1996:451-454

10 Pilliar R. Section 1 (Metals, alloys and ceramics). In: Handbook for Biomaterials Evaluation. 2nd ed. Philadelphia, PA: Taylor and Francis; 1999:13-37

11 Ti and Alloys: ASTM F 67, 136, 620 and 1295; Stainless Steel: ASTM F 138 and 621; Ni-Ti (Nitinol): ASTM F 2063 and 2025 (Terminology). West Conshohocken, PA American Society for Testing and Materials, Section 13, Volume 13.01, ASTM; 2012

12 Hadjipavlou A, Enker P, Dupuis P, Katzman S, Silver J. The causes of failure of lumbar transpedicular spinal instrumentation and fusion: a prospective study. Int Orthop 1996;20(1):35-42

13 Wedemeyer M, Parent S, Mahar A, Odell T, Swimmer T, Newton P. Titanium versus stainless steel for anterior spinal fusions: an analysis of rod stress as a predictor of rod breakage during physiologic loading in a bovine model. Spine 2007;32(1): 42-48

14 Burger EL, Baratta RV, King AG, et al. The memory properties of cold-worked titanium rods in scoliosis constructs. Spine (Phila Pa 1976) 2005;30(4):375-379 


\section{Commentary}

\author{
Vikas V. Patel, MD, $\mathrm{MA}^{1}$ \\ ${ }^{1}$ Denver Health Sciences, University of Colorado, Denver, Colorado, \\ United States
}

The authors report a unique case of an extension-distraction injury in a long construct fusion with plastic deformation of nickel-titanium rods. The patient had undergone a previous posterior spinal fusion from T2 to L2 with multilevel SmithPeterson osteotomies. The patient healed uneventfully and was seen 1 year later after a traumatic injury resulted in a fracture and extension of the rods, resulting in improved overall sagittal alignment. The patient was treated symptomatically and is doing well 1 year later without requiring further surgery. The authors surmised that the plastic deformation was due, in part, to the lower modulus of elasticity of the Ni-Ti alloy and improved pedicle screw fixation due to the biomaterial properties of the metal.

Although this appears to be a novel case report in the spine literature, rare cases involving traumatic deformation of intramedullary nails in long bone fractures have been reported in the orthopaedic trauma literature. ${ }^{1,2}$ These typically result in a deformity that require removal of the implant and fixation of the fracture. In this case, the plastic deformation and mechanism of injury improved the sagittal alignment of the patient without failure of the pedicle screw fixation or fracture of the rods. This may become predictable on the basis of lower modulus of elasticity of Ni-Ti alloy (75 gPa); however, there is little data on traumatic failure of any metal alloys used for posterior instrumentation. Given this, it would not be appropriate to assume a different outcome with other metal alloy implants.

Furthermore, there is a theoretical advantage to the use of titanium alloys in orthopedics because these metals more closely match the modulus of elasticity of bone. Bone ongrowth to titanium has been shown to be higher than an alternative, such as stainless steel. However, in one study, the increased on growth did not affect pullout strength, screw removal torque, or bone volume around the screw. ${ }^{3}$ Further evaluation is needed to determine if titanium alloy metals will ultimately improve fixation of pedicle screw constructs.

Thus, overall, we congratulate the authors on reporting this uncommon injury and positive outcome, but caution them in drawing far-reaching conclusions.

\section{References}

1 Stahel PF, Flierl MA, Morgan SJ, Smith WR. Management of a trochanteric fracture complicated by a bent solid intramedullary femoral nail in situ: description of technique. J Orthop Trauma 2010;24(3):e25-e30

2 Yip KMH, Leung KS. Treatment of deformed tibial intramedullary nail: report of two cases. J Orthop Trauma 1996;10(8):580-583

3 Christensen FB, Dalstra M, Sejling F, Overgaard S, Bünger C. Titanium-alloy enhances bone-pedicle screw fixation: mechanical and histomorphometrical results of titanium-alloy versus stainless steel. Eur Spine J 2000;9(2):97-103

\section{Editorial Perspective}

EBSJ thanks our colleagues from the University of Alabama, Birmingham, and Dr. Patel from the University of Colorado for their case report and commentary, respectively. This case was selected for discussion because of several interesting aspects:

- As to the forces at hand, it would be of some interest to know some more about the nature of the motor vehicle crash leading to this hyperextension injury, which is usually seen in patients with ankylosing spinal disorders only.

- With an increasing number of patients around the world having spinal hardware in their backs, the behavior of such an instrumented spinal column under unpredictable loading conditions such as incurred during trauma is relatively unknown and not amenable to in vitro testing. By convention, most surgeons would expect a spinal column to fail above or below an instrumented and fused spinal segment in case of major loading. In this case, this did not happen. The authors made the rather credible argument that a new injury in form of a hyperextension fracture occurred in the middle of the fused spine without actually breaking or

loosening the hardware, but rather creating a plastic deformation, similar to an ankylosed spine.

- There is a complex interplay between rate and type of fusion (circumferential versus posterolateral or other types), bone density within a fusion zone, and stiffness of a spinal implant. This creates several variables, which makes prediction of a failure model of a fused spine near impossible. As Dr. Patel has pointed out, titanium implants in pure or alloy variants have many advantageous features, which have made this the metal of choice for spinal stabilization procedures. The fact that this patient did not break above or below his fusion or through his implants is remarkable, but as pointed out by Dr. Patel, there may have been other factors more preeminently responsible for this occurrence rather than metallurgic ones. On the basis of the CT images, an incomplete union or at least incomplete remodeling of the fusion mass may have served as a stress riser in this extension failure as well. The injury CT scans do not show a bridging fusion across the disc spaces of the fusion zone, therefore inviting some extension failure to occur there. The 
maturity of a fusion mass is also relatively hard to determine. Most surgeons consider a segmentally instrumented arthrodesis be immature until 1-year postoperative, thus again creating a failure potential in an excessive loading situation. Therefore, the nature of the fusion across the spine may have had a major role in how this injury propagated. Caron et al in their review of ankylosing spine fractures commented on the role of the type of spinal fusion and the resultant fracture pattern. ${ }^{1}$

In the end, what counts most is that he is an incredibly fortunate young man. Despite being exposed to major kinetic forces, his spinal column, inclusive of his neural elements, survived functionally intact. One can make some argument that his implants actually saved him from what otherwise would have been a devastating spinal injury with likely cord compromise.

\section{Reference}

1 Caron T, Bransford R, Nguyen Q, Agel J, Chapman J, Bellabarba C. Spine fractures in patients with ankylosing spinal disorders. Spine (Phila Pa 1976) 2010;35(11):E458-E464 